\title{
Synthesis of spodumene and spodumene-zirconia composite powders using aqueous sol-gel method
}

\author{
N N GHOSH and P PRAMANIK* \\ Department of Chemistry, Indian Institute of Technology, Kharagpur 721 302, India \\ MS received 5 October 1996; revised 6 January 1997
}

\begin{abstract}
Pure spodumene and spodumene-zirconia $(5,10,15 \mathrm{~mol} \%)$ composite powders were prepared using aqueous sol-gel method employing lithium formate, aluminium formate, zirconium formate and tetraethoxy silane (TEOS) as starting materials in aqueous medium. The gels prepared by this method were dried at $100^{\circ} \mathrm{C}$ for $24 \mathrm{~h}$ and then calcined for $2 \mathrm{~h}$ at different temperatures ranging from $500^{\circ} \mathrm{C}$ to $800^{\circ} \mathrm{C}$. X-ray powder diffraction (XRD), differential thermal analysis (DTA), thermogravimetric analysis (TGA) and infra-red spectroscopy analysis (IR) were utilized to characterize the gel powders and calcined powders. Transmission electron microscope (TEM) was used to measure the average particle size of the calcined powders.
\end{abstract}

Keywords. Sol-gel; spodumene; zirconia; XRD; IR.

\section{Introduction}

A range of interesting properties makes $\beta$-spodumene $\left(\mathrm{Li}_{2} \mathrm{O} \cdot \mathrm{Al}_{2} \mathrm{O}_{3} \cdot 4 \mathrm{SiO}_{2}\right)$ useful material for commercial applications. It has been known to exhibit ultra-low thermal expansion, good thermal shock resistance, high-thermal stability and high-chemical durability (Yang et al 1991). It is largely used as refractory materials in industrial furnaces and as heat exchangers in gas turbines. Its other applications are found in cook top panels, stove windows, cookware etc (Wang 1994).

$\beta$-Spodumene has been commercially prepared by recrystallization of a solidified melt. There have been however, considerable difficulties experienced in sintering $\beta$-spodumene, prepared by this melting method, without using any sintering aid. The incorporation of sintering aid results in a large thermal expansion. Therefore, the preparation of homogeneous and fine $\beta$-spodumene powder has been considered to be very important (Wang 1994). Recently $\mathrm{ZrO}_{2}$ particles have been incorporated in the spodumene matrix to prepare $\mathrm{ZrO}_{2}$-toughened spodumene (Lathabai et al 1996).

Sol-gel method has been widely explored for synthesis of homogeneous multicomponent glass and ceramics (Roy 1987). Extensive studies have been carried out on the synthesis and the processing of spodumene using different precursor compounds. Some of them are (i) partial hydrolysis of tetraethoxy silane (TEOS) coupled with double alkoxide of lithium and aluminium (Suzuki $e t$ al 1991), (ii) hot pressing of hydrolysed product of TEOS, $\mathrm{LiNO}_{3}$ and $\mathrm{Al}\left(\mathrm{OC}_{4} \mathrm{H}_{9}\right)_{3}$ (Phallipon et al 1982; Veltri and Scola 1989), (iii) hydrolysis of alumina sol, silica sol and $\mathrm{LiNO}_{3}$ (Kobayashi et al 1990) and (iv) hydrolysis of TEOS, aluminium-s-butoxide and lithium methoxide (Yang et al 1991). However, the reactivities of metal alkoxides towards hydrolysis are sometimes very different, and consequently it has been very difficult to build a common molecular network in which various metal ions are included. Different hydrolysis rates of individual alkoxides may result in chemical inhomogeneity in the product leading to higher crystallization temperature or undesired

*For correspondence 
crystalline phases (Saha and Pramanik 1995). Tedious laboratory preparation of some metal alkoxides, their high cost and commercial unavailability have led to the use of inorganic salts in sol-gel technique (Oldhman 1968; Levene and Thomas 1972). The most commonly used inorganic precursors are metal nitrates and chlorides. However, when metal halides or nitrates have been used over a certain concentration range (usually about $5 \mathrm{~mol} \%$ ) to prepare silicate gels, the salts separated out during drying, causing chemical inhomogeneity. It has been reported that the use of weak acid salts of metals (e.g. oxalates and formates) caused no such segregation problem when they reacted with TEOS in aqueous medium to form multicomponent silicate gels. This method of preparation of multicomponent silicate gel in aqueous medium was termed as 'aqueous sol-gel method' (Chakraborti and Pramanik 1990; Saha and Pramanik 1993, 1995). In this paper, we report the synthesis of $\beta$-spodumene and spodumene-zirconia composite powders using aqueous sol-gel technique. Here lithium formate, aluminium formate, zirconium formate and TEOS were used as starting materials in aqueous medium.

\section{Experimental}

We have used lithium carbonate (99 wt \%), (BDH Chemicals, India), aluminium nitrate nona hydrate (98.5 wt\%), (BDH Chemicals, India), zirconium oxychloride octahydrate (98 wt\%) (Aldrich Chemicals), and formic acid (85 wt\%), (Qualigen Fine Chemicals, India) for preparation of lithium formate, aluminium formate and zirconium formate. Freshly precipitated aluminium hydroxide, zirconium hydroxide were prepared by adding ammonium hydroxide to the corresponding metal salt solutions. After filtering and washing with distilled water these hydroxides were then reacted with $50 \%$ aqueous formic acid solution to give the corresponding metal formate solutions. Lithium formate was prepared by reacting lithium carbonate with aqueous formic acid solution. Metal formate solutions containing the required amount of metal ions were then added to tetraethoxy

Table 1. Experimental details of the preparation of gels of spodumene and spodumene-zirconia systems.

\begin{tabular}{lccccc}
\hline Composition & Sample $^{\mathrm{a}}$ & $\begin{array}{c}\mathrm{Vol}^{\mathrm{b}} \\
(\mathrm{ml})\end{array}$ & $\mathrm{pH}^{\mathrm{c}}$ & $\begin{array}{c}\mathrm{Temp}^{\mathrm{d}} \\
\left({ }^{\circ} \mathrm{C}\right)\end{array}$ & $\begin{array}{l}t_{\text {gel }}^{\mathrm{c}} \\
(\mathrm{h})\end{array}$ \\
\hline $\mathrm{Li}_{2} \mathrm{O} \cdot \mathrm{Al}_{2} \mathrm{O}_{3} \cdot 4 \mathrm{SiO}_{2}$ & $\mathrm{SZ0}$ & 150 & $1 \cdot 3$ & 60 & $4 \cdot 5$ \\
$\begin{array}{l}\mathrm{Li}_{2} \mathrm{O} \cdot \mathrm{Al}_{2} \mathrm{O}_{3} \cdot 4 \mathrm{SiO}_{2} \\
\text { with } 5 \mathrm{~mol}_{0} \mathrm{ZrO}_{2}\end{array}$ & $\mathrm{SZ5}$ & 150 & $1 \cdot 2$ & 60 & 5 \\
$\begin{array}{l}\mathrm{Li}_{2} \mathrm{O} \cdot \mathrm{Al}_{2} \mathrm{O}_{3} \cdot 4 \mathrm{SiO}_{2} \\
\text { with } 10 \mathrm{~mol}_{2} \mathrm{ZrO}_{2}\end{array}$ & $\mathrm{SZ10}$ & 160 & $1 \cdot 2$ & 60 & 5 \\
$\begin{array}{l}\mathrm{Li}_{2} \mathrm{O} \cdot \mathrm{Al}_{2} \mathrm{O}_{3} \cdot 4 \mathrm{SiO}_{2} \\
\text { with } 15 \mathrm{~mol}_{2} \mathrm{ZrO}_{2}\end{array}$ & $\mathrm{SZ15}$ & 160 & $1 \cdot 1$ & 60 & 5 \\
\hline
\end{tabular}

${ }^{a}$ In all sample solutions, the amount of TEOS used is $10 \mathrm{ml}(0.04389 \mathrm{~mole})$ and the amount of constituents are according to their molecular proportions. Aqueous formic acid is used to make the metal formate solutions.

${ }^{b}$ Initial volume of the sample solutions including TEOS.

'Initial $\mathrm{pH}$ of the sample solution after adding TEOS to the mixed metal formate solution.

'Temperature mentioned during the formation of gel.

${ }^{\mathbf{e}} t_{\text {gel }}$ Time required for the formation of gel. 
silane (98 wt \% of Fluka Chemicals) (TEOS) according to the compositions. The specific conditions and experimental details are listed in table 1. At the beginning of mixing, TEOS and the aqueous solutions of metal formates were immiscible. A homogeneous solution was obtained after about $30 \mathrm{~min}$ of hydrolysis of TEOS under rapid stirring using a magnetic stirrer. Slow stirring and heating was continued until the formation of gel.

The gels were dried at $100^{\circ} \mathrm{C}$ for $24 \mathrm{~h}$ on a water bath and then ground to powders. These powders were then gradually heated at $5^{\circ} \mathrm{C} \mathrm{min}^{-1}$ and calcined in air for $2 \mathrm{~h}$ to temperature ranging from $500^{\circ} \mathrm{C}$ to $800^{\circ} \mathrm{C}$.

Infrared spectra of these samples were obtained in $\mathrm{KBr}$ medium using Perkin-Elmer 883 IR spectrophotometer. Room temperature X-ray diffraction (XRD) patterns were obtained using a Philips X-ray powder diffractometer PW 11710 and $\mathrm{CuK} \alpha$ radiation. Thermogravimetric analysis (TGA) and differential thermal analysis (DTA) were conducted at a heating rate of $10^{\circ} \mathrm{C} \mathrm{min}^{-1}$ in air employing Shimadzu DT-40 thermal analyser. The average particle size of the calcined powders were measured using a transmission electron microscope (TEM) of Phillips CM12.

\section{Results and discussion}

TGA of dried gel powders exhibited three-stage weight loss of the dried gel powders. The total weight loss of the dried gels was about $60 \mathrm{wt} \%$. There was no significant

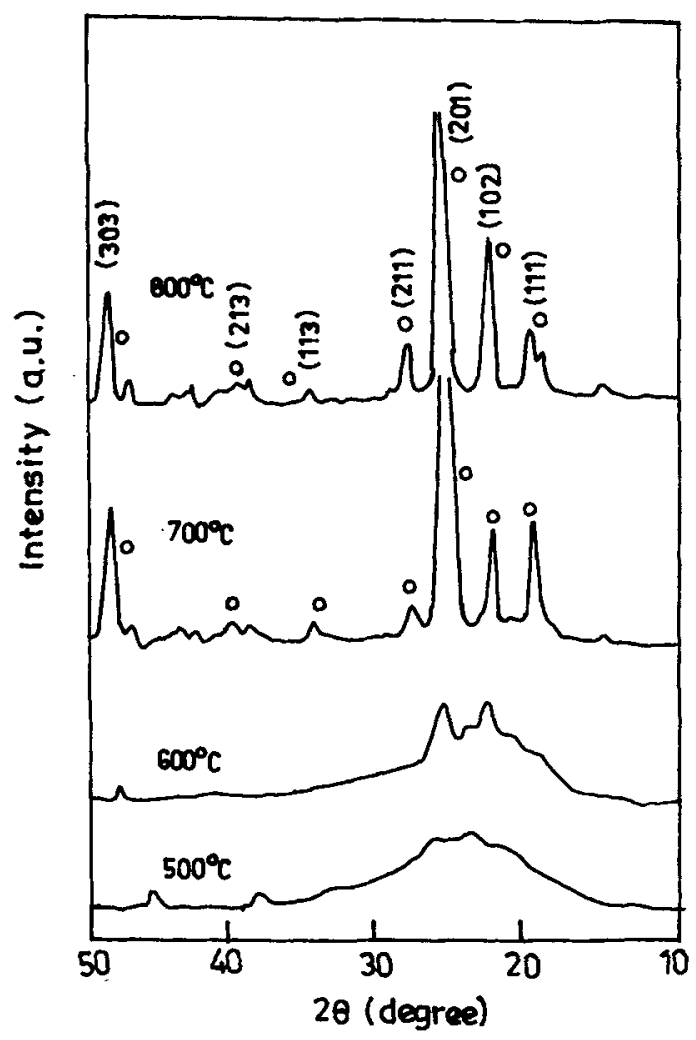

Figure 1. Powder X-ray diffractograms of sample SZ0 after calcination at $500^{\circ} \mathrm{C}, 600^{\circ} \mathrm{C}$, $700^{\circ} \mathrm{C}, 800^{\circ} \mathrm{C}$, for $2 \mathrm{~h}$. ((O): $\beta$-spodumene). 


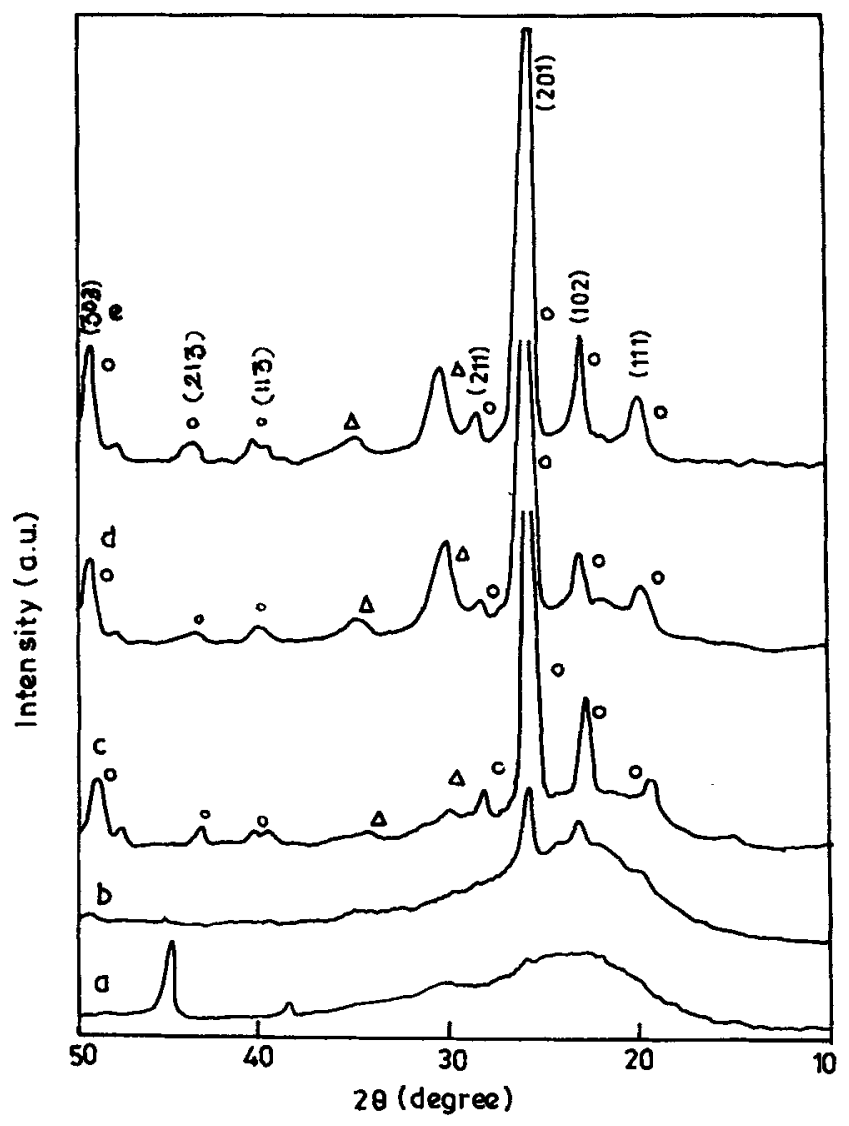

Figure 2. Powder X-ray diffractograms of samples SZ5, SZ10 and SZ15 after calcination at different temperatures for $2 \mathrm{~h}$. (a) SZ15 at $700^{\circ} \mathrm{C}$, (b) SZ10 at $700^{\circ} \mathrm{C}$, (c) SZ5 at $800^{\circ} \mathrm{C}$, (d) SZ15 at $800^{\circ} \mathrm{C}$, (e) SZ10 at $800^{\circ} \mathrm{C},(\mathrm{O}): \beta$-spodumene, $(\Delta)$ : tetragonal zirconia.

weight change beyond $550^{\circ} \mathrm{C}$. The DTA curves show an endothermic peak at about $90^{\circ} \mathrm{C}$ corresponding to the release of loosely bound water and an exothermic peak at about $270^{\circ} \mathrm{C}$ corresponding to the decomposition and oxidation of formate salts.

Room temperature XRD patterns for all the samples calcined at different temperatures were taken and some selected patterns are shown in figures 1 and 2 . The effect of calcination on the evolution of $\beta$-spodumene phase in sample SZ0 and $\beta$-spodumene and zirconia phases in samples SZ5, SZ10 and SZ15 are as follows: (a) all the dried gel powders were amorphous. This amorphous phase was retained when the gel powder of SZ0 was calcined up to $600^{\circ} \mathrm{C}$ and up to $700^{\circ} \mathrm{C}$ for the gel powders of SZ5, SZ10 and $\mathrm{SZ15}$, (b) the XRD peaks, corresponding to $\beta$-spodumene phase, appeared for sample SZ0 when the calcination temperature was $700^{\circ} \mathrm{C}$ or above and (c) samples SZ5, SZ10 and SZ15 produced $\beta$-spodumene and tetragonal zirconia phases of crystallization when calcined at $800^{\circ} \mathrm{C}$ for $2 \mathrm{~h}$. The crystalline phases of all the samples calcined at different temperatures for $2 \mathrm{~h}$ are summarized in table 2 .

Several structural changes in the gel powders due to calcination at different temperatures were also observed by IR spectroscopic analysis. Figures 3 and 4 show the IR spectra of samples SZ0, SZ5, SZ10 and SZ15 after calcination at different 
Table 2. Summary of $X$-ray powder diffraction studies in the spodumene and spodumene-zirconia composites during heat treatment.

\begin{tabular}{lcccc}
\hline & \multicolumn{4}{c}{ Temperature of heat treatment $\left({ }^{\circ} \mathrm{C}\right)(2 \mathrm{~h})$} \\
\cline { 2 - 5 } Sample & 500 & 600 & 700 & 800 \\
\hline SZ0 & A & A & $\beta$ & $\beta$ \\
SZ5 & A & A & A & $\beta+t$ \\
SZ10 & A & A & A & $\beta+\mathrm{t}$ \\
SZ15 & A & A & A & $\beta+t$ \\
\hline
\end{tabular}

A: amorphous; $\beta$ : $\beta$-spodumene; t: tetragonal zirconia.

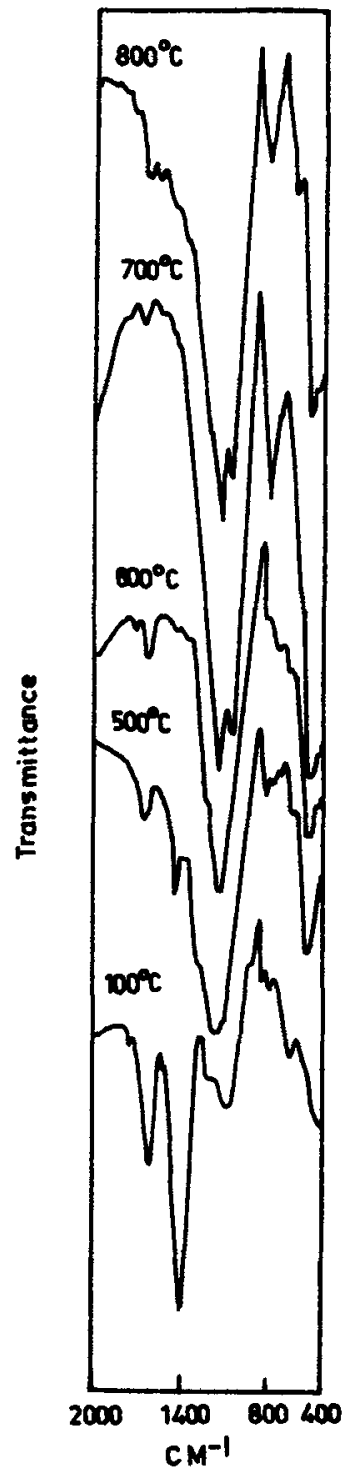

Figure 3. IR spectra of dried gel powder of sample $\mathrm{SZO}$ at $100^{\circ} \mathrm{C}$ and after calcination at $500^{\circ} \mathrm{C}, 600^{\circ} \mathrm{C}, 700^{\circ} \mathrm{C}$ and $800^{\circ} \mathrm{C}$ for $2 \mathrm{~h}$. 


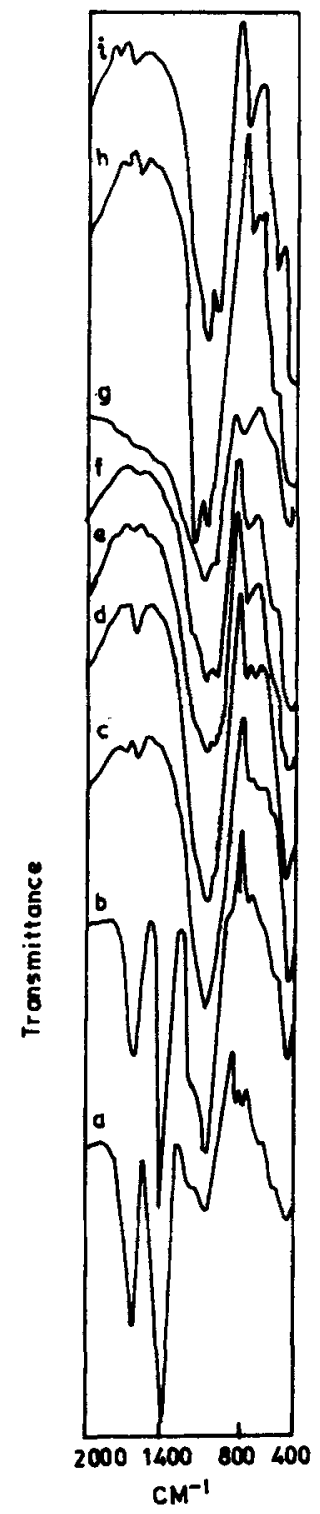

Figure 4. IR spectra of dried gel powders of sample SZ5, SZ10, SZ15 at $100^{\circ} \mathrm{C}$ and after calcination at different temperatures for $2 \mathrm{~h}$. (a) $\mathrm{SZ10}$ at $100^{\circ} \mathrm{C}$, (b) $\mathrm{SZ5}$ at $100^{\circ} \mathrm{C}$, (c) SZ10 at $600^{\circ} \mathrm{C}$, (d) SZ5 at $600^{\circ} \mathrm{C}$, (e) SZ5 at $700^{\circ} \mathrm{C}$, (f) SZ15 at $700^{\circ} \mathrm{C}$, (g) SZ5 at $800^{\circ} \mathrm{C}$, (b) SZ10 at $800^{\circ} \mathrm{C}$, and (i) $\mathrm{SZ} 15$ at $800^{\circ} \mathrm{C}$.

temperatures. The vibrational frequencies of the dried gel powders and calcined powders of the samples at different temperatures and their assignments are summarized in table 3. With the increase of calcination temperatures the striking features of IR spectras observed are as follows: (a) in the gel powders dried at $100^{\circ} \mathrm{C}$, the characteristic absorption band of the formate group at about $1380 \mathrm{~cm}^{-1}$ was observed. The disappearance of this band after calcination at higher temperatures confirmed that 
Table 3. IR bands (in $\mathrm{cm}$ ) of gel powders of SZ0, SZ5, SZ10 and SZ15 after heat treatment.

\begin{tabular}{|c|c|c|c|c|c|}
\hline \multirow{2}{*}{$\begin{array}{l}\text { Relevant assignment } \\
\text { lit data }\end{array}$} & \multirow{2}{*}{$\begin{array}{l}\text { Temp. } \\
\left({ }^{\circ} \mathrm{C}\right)\end{array}$} & \multicolumn{4}{|c|}{ Samples } \\
\hline & & SZ0 & SZ5 & SZ10 & SZ15 \\
\hline \multirow[t]{2}{*}{1380 Carb } & 100 & $1392 s$ & $1387 \mathrm{~s}$ & $1397 \mathrm{~s}$ & $1390 \mathrm{~s}$ \\
\hline & 500 & $1385 \mathrm{vw}$ & - & - & - \\
\hline \multirow[t]{5}{*}{1200 SiOSiLO } & 100 & $1200 \mathrm{sh}$ & $1180 \mathrm{sh}$ & $1200 \mathrm{sh}$ & 1190 sh \\
\hline & 500 & $1206 \mathrm{sh}$ & $1189 \mathrm{sh}$ & $1200 \mathrm{sh}$ & $1189 \mathrm{sh}$ \\
\hline & 600 & $1206 \mathrm{sh}$ & $1200 \mathrm{sh}$ & 1199sh & 1198sh \\
\hline & 700 & $1206 \mathrm{sh}$ & $1200 \mathrm{sh}$ & $1200 \mathrm{sh}$ & $1200 \mathrm{sh}$ \\
\hline & 800 & 1210 sh & $1186 \mathrm{sh}$ & $1190 \mathrm{sh}$ & $1190 \mathrm{sh}$ \\
\hline \multirow[t]{5}{*}{1080 SiOSiTO } & 100 & $1072 b$ & $1070 \mathrm{~s}$ & $1053 \mathrm{~m}$ & $1070 \mathrm{~s}$ \\
\hline & 500 & $1079 \mathrm{~b}$ & $1075 s$ & $1060 \mathrm{~m}$ & $1075 \mathrm{~s}$ \\
\hline & 600 & $1070 \mathrm{~s}$ & $1075 \mathrm{~s}$ & $1070 \mathrm{~m}$ & $1075 s$ \\
\hline & 700 & $1080 \mathrm{vs}$ & 1074vs & 1084vs & $1079 \mathrm{vs}$ \\
\hline & 800 & $1079 \mathrm{vs}$ & 1083vs & $1079 \mathrm{vs}$ & 1081vs \\
\hline \multirow[t]{2}{*}{$1070 \mathrm{Sp}$} & 700 & $1009 \mathrm{~s}$ & - & $\longrightarrow$ & - \\
\hline & 800 & $1015 \mathrm{~s}$ & $1009 \mathrm{~s}$ & $1008 s$ & $1007 \mathrm{~s}$ \\
\hline \multirow{5}{*}{800 SiOSism } & 100 & $826 w$ & $790 w$ & $809 w$ & $800 w$ \\
\hline & 500 & $790 w$ & $785 w$ & $805 w$ & $800 \mathrm{w}$ \\
\hline & 600 & $762 w$ & $789 w$ & $785 w$ & $790 \mathrm{w}$ \\
\hline & 700 & $771 \mathrm{~s}$ & $789 w$ & $784 \mathrm{sh}$ & $791 \mathrm{sh}$ \\
\hline & 800 & $773 \mathrm{~s}$ & $780 \mathrm{~m}$ & $761 \mathrm{~m}$ & $764 m$ \\
\hline 655 form & 100 & - & $660 \mathrm{~s}$ & $652 \mathrm{sh}$ & $655 \mathrm{~d}$ \\
\hline 600 tetra & 800 & - & 600 & 599wsh & 599wsh \\
\hline $560 \mathrm{Sp}$ & 800 & 554 & $560 \mathrm{sh}$ & $555 \mathrm{sh}$ & - \\
\hline \multirow[t]{5}{*}{460 SiOSibm } & 100 & $451 \mathrm{~m}$ & $451 \mathrm{~m}$ & $456 \mathrm{~m}$ & $450 \mathrm{~m}$ \\
\hline & 500 & $467 \mathrm{mb}$ & $450 \mathrm{~m}$ & $456 \mathrm{~m}$ & $445 m$ \\
\hline & 600 & $466 s$ & $455 \mathrm{~m}$ & $450 \mathrm{~m}$ & $455 \mathrm{~m}$ \\
\hline & 700 & $432 \mathrm{~s}$ & $465 \mathrm{~s}$ & $460 \mathrm{~s}$ & $465 \mathrm{~s}$ \\
\hline & 800 & $439 s$ & $447 \mathrm{~s}$ & $445 \mathrm{~s}$ & $446 s$ \\
\hline
\end{tabular}

a) Carb: Carboxylate group; SiOSiLO: Asymmetric stretching vibration-longitudinal optics; SiOSism: Network $\mathrm{Si}-\mathrm{O}-\mathrm{Si}$ symmetric stretching vibration; SiOSiTO: asymmetric stretching vibration-transverse optics; SiOSibm: Network $\mathrm{Si}-\mathrm{O}-\mathrm{Si}$ bending vibration; form: zirconium-formate; tetra: tetragonal zirconia; $\mathrm{Sp}$ : spodumene.

b) v: very; w: weak; m: medium; s: strong; sh: shoulder.

the decomposition of metal formates occurs due to calcination, (b) the characteristic bands of $\beta$-spodumene at about $1017,765,560 \mathrm{~cm}^{-1}$ (Gadsden 1975) were observed in the calcined powders of sample SZ0 when calcined at $600^{\circ} \mathrm{C}$ and in the calcined powders of sample SZ5, SZ10 and SZ15 when calcined at $700^{\circ} \mathrm{C}$ and higher temperatures. The characteristic peak of tetragonal zirconia (Saha and Pramanik 1993) at about $600 \mathrm{~cm}^{-1}$ was observed in the sample SZ5, SZ10 and SZ15 when calcination temperature was $800^{\circ} \mathrm{C}$.

The average particle size of the calcined powders were measured using TEM. The particle sizes of spodumene and spodumene-zirconia composite are listed in table 4. The average size of the particles were in nanometre scale and were observed to increase with increase in calcination temperature (figure 5). The crystallite sizes of $\beta$-spodumene and tetragonal zirconia phases were also calculated by $\mathrm{X}$-ray peak broadening method and the crystallite sizes are listed in table 5. 

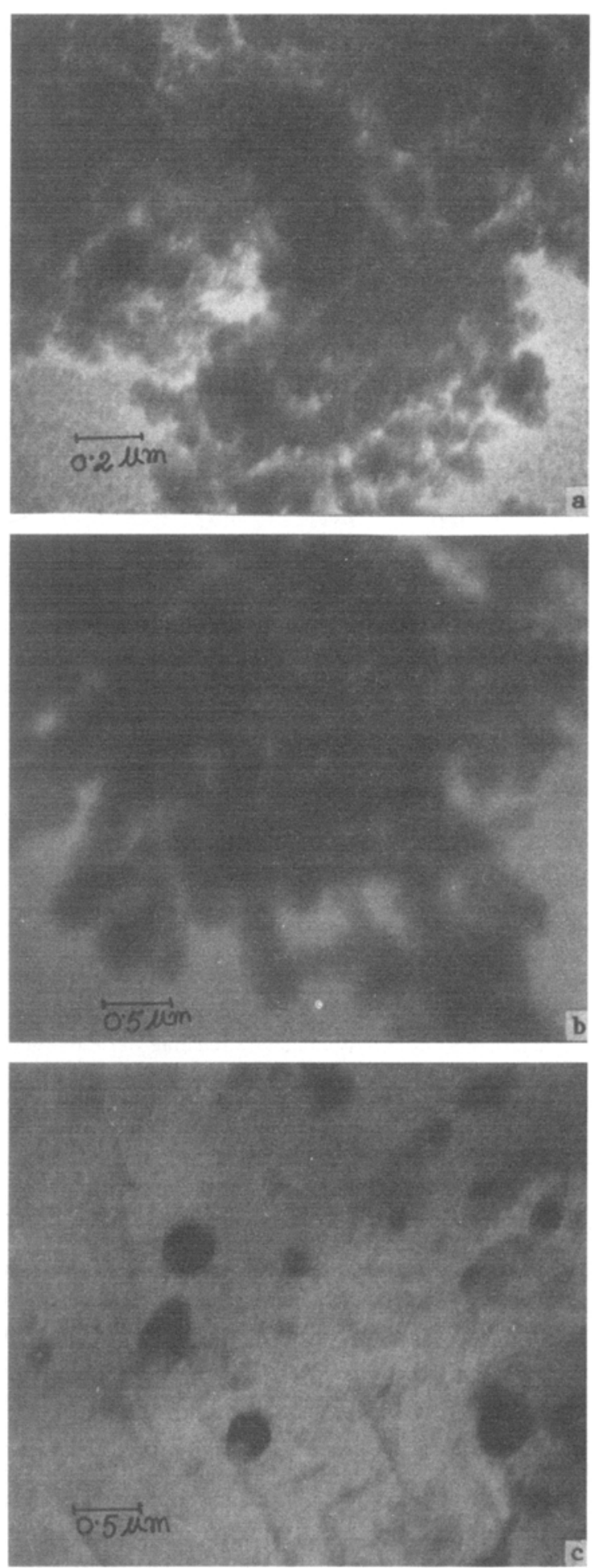

Figure 5. a-c. 

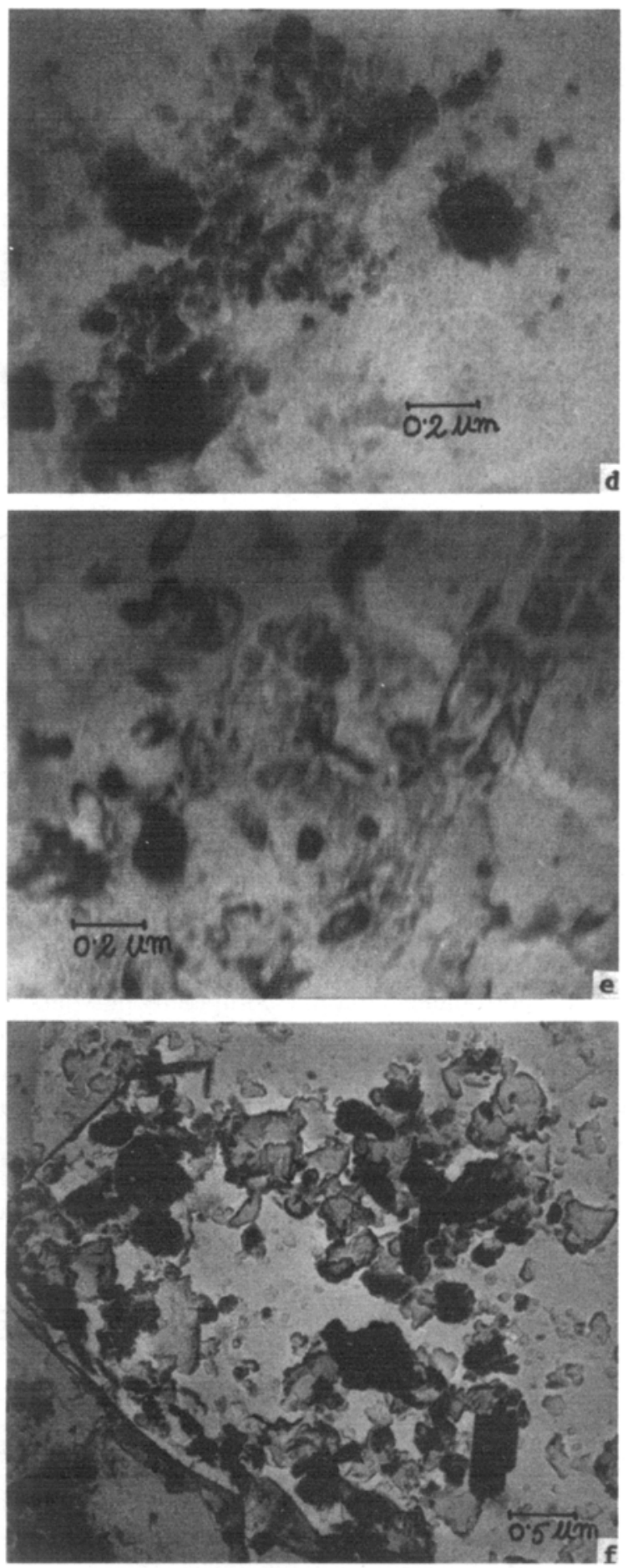

Figure 5. TEM micrographs of spodumene and spodumene-zirconia composite powders after calcination at different temperatures: (a) $\mathrm{SZ} 0$ at $600^{\circ} \mathrm{C},\left(\right.$ b) $\mathrm{SZ} 0$ at $700^{\circ} \mathrm{C}$, (c) $\mathrm{SZO}$ at $800^{\circ} \mathrm{C}$, (d) $\mathrm{SZ5}$ at $800^{\circ} \mathrm{C}$, (e) $\mathrm{SZ} 10$ at $800^{\circ} \mathrm{C}$ and (f) $\mathrm{SZ} 15$ at $800^{\circ} \mathrm{C}$. 
Table 4. Average particle size $( \pm 10 \mathrm{~nm})$ of the samples after calcination at different temperatures obtained from TEM.

\begin{tabular}{lccc}
\hline & \multicolumn{3}{c}{ Temperature of heat treatment $\left({ }^{\circ} \mathrm{C}\right)(2 \mathrm{~h})$} \\
\cline { 2 - 4 } Samples & 600 & 700 & 800 \\
\hline SZ0 & $150 \mathrm{~nm}$ & $170 \mathrm{~nm}$ & $200 \mathrm{~nm}$ \\
SZ5 & $160 \mathrm{~nm}$ & $200 \mathrm{~nm}$ & $310 \mathrm{~nm}$ \\
SZ10 & $175 \mathrm{~nm}$ & $190 \mathrm{~nm}$ & $330 \mathrm{~nm}$ \\
SZ15 & $190 \mathrm{~nm}$ & $230 \mathrm{~nm}$ & $275 \mathrm{~nm}$ \\
\hline
\end{tabular}

Table 5. Average particle size of the powders calcined at $800^{\circ} \mathrm{C}$ for $2 \mathrm{~h}$ measured by $\mathrm{X}$-ray peak broadening.

\begin{tabular}{ll}
\hline Sample & Particle size \\
\hline SZ0 & $\beta(180 \mathrm{~nm})$ \\
SZ5 & $\beta(250 \mathrm{~nm})$ \\
& $+\mathrm{t}(25 \mathrm{~nm})$ \\
SZ10 & $\beta(280 \mathrm{~nm})$ \\
& $+\mathrm{t}(40 \mathrm{~nm})$ \\
SZ15 & $\beta(285 \mathrm{~nm})$ \\
& $+\mathrm{t}(45 \mathrm{~nm})$ \\
\hline
\end{tabular}

$\beta$ : $\beta$-spodumene; t: tetragonal zirconia.

\section{Conclusion}

Ultrafine $\beta$-spodumene and spodumene-zirconia composite powders were easily synthesized by using aqueous sol-gel method. X-ray diffraction patterns and IR spectras confirm the formation of $\beta$-spodumene phase and tetragonal zirconia phase occurring due to calcination of dried gel powders. The formation of $\beta$-spodumene and tetragonal zirconia phase occurs at comparatively low temperature due to the atomic scale mixing of the constituent elements in gels.

In conclusion, it can be stated that, this method of using aqueous solutions of metal formate salts for preparation of multicomponent gel offers a cost-effective and technically simpler alternative to the rather expensive all alkoxide route.

\section{References}

Chakraborti S and Pramanik P 1990 J. Mater. Sci. Lett. 91135

Gadsden J A 1975 Infrared spectra of minerals and related inorganic compounds (London: Butterworth) p 193, 64

Kobayashi H, Ishibashi N, Akiba T and Mitamura T 1990 J. Ceram. Soc. Jpn. 98703

Lathabai S, Hey D G, Wagner F and Claussen N 1996 J. Am. Ceram. Soc. 79248

Levene L and Thomas I M 1972 US Patent 3640093

Oldhman C 1968 Prog. Inorg. Chem. 10223

Phallipon J, Prassas M and Zarzycki J 1982 J. Non-Cryst. Solids 4817

Roy R 1987 Science 2381664 
Saha S K and Pramanik P 1993 J. Non-Cryst. Solids 15931

Saha S K and Pramanik P 1995 J. Mater. Sci. 302855

Suzuki H, Takahashi J and Saito H 1991 J. Chem. Soc. Jpn. 101312

Veltri R and Scola D 1989 Powder Metall. Int. 2118

Wang M 1994 J. Mater. Res. 92290

Yang J S, Sakka S, Yoko T and Kozaka H 1991 J. Mater. Sci. 261827 